\title{
Hospital emergency department visits by ambulance for nontraumatic tooth pain in the USA
}

This article was published in the following Dove Press journal:

Clinical, Cosmetic and Investigational Dentistry

\author{
Jonathan D Shenkin' \\ John Warren ${ }^{2}$ \\ Charles Spanbauer ${ }^{3}$ \\ Elaye Okunseri ${ }^{4}$ \\ Aniko Szabo ${ }^{3}$ \\ Christopher Okunseri ${ }^{4}$ \\ 'Department of Health Policy and \\ Health Services Research, Boston \\ University School of Dental Medicine, \\ Boston, MA, USA; ${ }^{2}$ Department \\ of Preventive and Community \\ Dentistry, University of lowa, College \\ of Dentistry and Dental Clinics, \\ lowa City, IA, USA; ${ }^{3}$ Division of \\ Biostatistics, Institute of Health and \\ Society, Medical College of Wisconsin, \\ Milwaukee, WI, USA; ${ }^{4}$ Department \\ of Clinical Services, Marquette \\ University School of Dentistry, \\ Milwaukee, WI, USA
}

Objective: This study examined the prevalence of ambulance use for nontraumatic tooth pain (NTP) visit to emergency departments (EDs) and the factors associated with ambulance use for NTP in the USA.

Materials and methods: Data from the National Hospital Ambulatory Medical Care survey conducted in the USA from 2003 to 2012 were analyzed. Descriptive statistics were obtained, and multivariable logistic regression was used to determine associations with ambulance use for NTP. Results: The total proportion of ED visits due to NTP by ambulance was $1.1 \%$, lowest in 2008 $(0.43 \%)$ and highest in $2011(2.28 \%)$. The proportion of ED visits due to NTP by ambulance was highest among public insurance enrollees (1.9\%), Hispanics (2.3\%) and those aged 45-64 years $(2.7 \%)$. In the multivariable analysis, those aged 45-64 years had approximately four times higher odds of an ED visit for NTP by ambulance compared to those aged 25-44 years. Conclusion: This study demonstrates that transport to EDs by ambulance for NTP does occur at a measurable rate and adults aged 45-64 years had significantly higher odds of ED visits for NTP by ambulance.

Keywords: adults, dental caries, toothache, emergency department services

\section{Introduction}

Limited access to dental care is a significant problem and it contributes to disparities in oral health in the USA. Due to this limited access, many people have untreated nontraumatic dental problems and they sometimes turn to emergency departments (EDs) for care. ${ }^{1}$ While this represents a "last resort" for patients seeking care for nontraumatic tooth pain (NTP), EDs are poorly equipped to treat dental problems - for they typically have no dentist on staff and lack basic dental equipment or instruments. These patients who turn to EDs for NTP pose a serious problem to the health care system because of the associated workforce implications and cost. ${ }^{1,2}$

Potentially compounding this phenomenon are ED visits for NTP where the patient arrives by ambulance. This means of transportation adds to the cost and inefficiency associated with ED visits for a potentially avoidable dental condition that is best treated by a dental health professional in a dental office. Ascertaining how much is the financial burden is challenging because the costs of using ambulances are not widely reported in the literature. The Washington Post recently reported that there is great variability in the costs of using ambulances, from hundreds to thousands of dollars. ${ }^{3}$ While it is very difficult to define whether a nontraumatic dental condition visit to $\mathrm{ED}$ is considered urgent or non-urgent, the fact remains that the use of emergency medical services to transport patients with a non-urgent medical condition for which
Correspondence: Christopher Okunser Department of Clinical Services Room 356, Marquette University School of Dentistry, PO Box I88I Milwaukee, WI, USA

Tel +l $4 \mid 42886524$

Fax +l 4142883586

Email christopher.okunseri@marquette. edu 
alternative transportation is most appropriate is considered inappropriate ambulance use., ${ }^{4,5}$

Meisel et al reported that roughly $14 \%$ of all ED patients get to the ED by ambulance in the USA. ${ }^{6}$ Ambulances offer a vital means of transportation to hospital EDs in lifethreatening situations. For example, $52 \%$ of patients reporting poisoning who attend an ED were transported by ambulance. ${ }^{7}$ If ambulances are sidetracked by responding to non-acute emergencies, which is often the case with NTP, this could pose a risk to others in need of urgent care and add to the burden of the health care system. The use of ED for NTP visits where the patient is transported by an ambulance is of concern to health care advocates and policymakers. In addition, ED is a major entry point into the health care system for many people in the USA. Yet, there is virtually nothing known about the characteristics of individuals with NTP who arrive at the ED by ambulance.

Thus, the purpose of this study is to investigate the characteristics and proportion of patients with NTP who visit ED by ambulance and the associated factors utilizing a nationally representative dataset. Our hypothesis is that ED visits by ambulance for NTP does occur with some frequency and may potentially add some burden to the health care system. Investigators recognize that there might be individuals with life-threatening dental-related conditions that require an ambulance. However, this study is strictly about NTP for which the use of an ambulance is clearly unnecessary based on evidence in the literature.

\section{Materials and methods}

The study used the National Hospital Ambulatory Medical Care Survey (NHAMCS) tailored toward understanding of utilization of ambulatory care in non-institutional general and short-stay hospitals within the 50 States and District of Columbia during the years 2003-2012. To minimize and eliminate misunderstanding in the administration of the survey, specially trained interviewers visited the selected EDs to facilitate the initial steps to participating in the survey. A four-stage probability sampling design was used to help eliminate any potential selection bias. Included in the NHAMCS were sections pertinent to socioeconomic status, race/ethnicity, financing of care, information regarding clinical presentation, diagnosis and treatment, as well as the times and dates at which the sampled patients presented in the emergency facilities. The study population was defined based on tooth pain as the self-reported primary reason for visit variable, which was coded using the internal systems developed by the National Center for Health Statistics. Spe- cifically, the codes 15,000 (symptoms of teeth and gums), 15,001 (toothache), 15,002 (gum pain) and 15,003 (bleeding gums) were included, while codes indicating orofacial trauma or infection were not included. The authors chose self-reported primary reasons because they best represent the actual reasons for the ambulance call and they are closely aligned with the physician diagnosis based on the International Classification of Diseases and Related Health Problems codes, which occurs after the patient has arrived at the ED. In addition, patients with severe oro-facial conditions (eg, Ludwig's angina) requiring hospitalization or admitted for care were not included in this study because they may truly require the use of an ambulance. This study was reviewed and approved by Marquette University's Institutional Review Board.

\section{Measures}

The primary outcome for this study was the proportion of patients with NTP, who arrived at the ED by ambulance. The question of how patients arrive at the ED has varied over the years, but in this study, we only included the specific question that asked whether the patient arrived by ambulance. Independent variables included age groups $(<15,15-24,25-44$, 45-64 and $\geq 65$ ), sex, race/ethnicity recoded as non-Hispanic White, non-Hispanic Black or Hispanic, expected source of payment grouped as uninsured, private insurance, public insurance, other or unknown, region of hospital location and the day of week of the visit classified as weekday or weekend.

\section{Statistical analysis}

All analyses were adjusted for survey design using the weights and cluster variables provided in the NHAMCS-ED survey. A Rao-Scott chi-squared test was used to examine differences in ambulance use between patient groups and over time. Based on findings from the descriptive statistics, calendar year was treated as a linear continuous predictor in the multivariable analysis. The primary analysis evaluating the effect of the independent variables on the likelihood of having arrived by ambulance was performed using multiple logistic regression. No model selection or pre-screening of the predictors was performed; they were selected a priori by the research team. Two-sided $P$-values are reported, and a $5 \%$ significance level is used throughout. The analyses were performed using SAS 9.4 (SAS Institute, Cary NC, USA).

\section{Results}

Overall, $1.1 \%$ of visits to ED due to tooth pain were by ambulance. Table 1 represents the study population char- 
Table I Study population characteristics and bivariate analysis

\begin{tabular}{|c|c|c|c|c|c|c|c|c|}
\hline Predictor & Total & $\begin{array}{l}\text { Weighted } \\
\text { total } \\
\text { (in } 1,000 s \text { ) }\end{array}$ & $\%$ Level & Frequency & $\begin{array}{l}\text { Weighted } \\
\text { frequency } \\
\text { (in I,000s) }\end{array}$ & $\begin{array}{l}\text { Percent (\%) } \\
\text { ambulance }\end{array}$ & $\begin{array}{l}\text { Standard } \\
\text { error: } \\
\text { ambulance }\end{array}$ & $P$-value \\
\hline Overall & 3,649 & 13,338 & 100 & 50 & 151 & 1.13 & & \\
\hline Payment type & & & & & & & & 0.01 \\
\hline Unknown & 245 & 893 & 6.7 & 5 & 11.4 & 1.28 & 0.57 & \\
\hline Private insurance & 680 & 2,566 & 19.2 & 4 & 12.8 & 0.50 & 0.30 & \\
\hline Public insurance & 1,394 & 4,945 & 37.1 & 28 & 95.4 & 1.93 & 0.57 & \\
\hline Other & 66 & 261 & 1.9 & 2 & 4.3 & 1.65 & 1.29 & \\
\hline Uninsured & 1,264 & 4,674 & 35.0 & 11 & 27.4 & 0.59 & 0.20 & \\
\hline Age group & & & & & & & & 0.03 \\
\hline$<15$ years & 165 & 617 & 4.6 & 3 & 9.5 & 1.54 & 1.32 & \\
\hline 15-24 years & 899 & 3,319 & 24.9 & 15 & 37.9 & 1.14 & 0.36 & \\
\hline $25-44$ years & 2,019 & 7,270 & 54.5 & 19 & 48.2 & 0.66 & 0.18 & \\
\hline 45-64 years & 509 & 1,952 & 14.6 & 11 & 52.1 & 2.67 & 1.23 & \\
\hline$\geq 65$ years & 57 & 181 & 1.4 & 2 & 3.5 & 1.95 & $\mathrm{I} .4 \mathrm{I}$ & \\
\hline Sex & & & & & & & & 0.44 \\
\hline Male & $I, 96 \mid$ & 7,354 & 55.1 & 27 & 94.4 & 1.28 & 0.37 & \\
\hline Female & 1,688 & 5,984 & 44.9 & 23 & 56.9 & 0.95 & 0.26 & \\
\hline Race/ethnicity & & & & & & & & 0.23 \\
\hline Non-Hispanic White & 2,359 & 8,781 & 65.8 & 24 & 85.3 & 0.97 & 0.31 & \\
\hline Non-Hispanic Black & 941 & 3,338 & 25.0 & 17 & 38.5 & 1.15 & 0.38 & \\
\hline Hispanic & 349 & 1,219 & 9.1 & 9 & 27.5 & 2.25 & 0.91 & \\
\hline Day of week & & & & & & & & 0.69 \\
\hline Weekend & 1,160 & 4,147 & 31.1 & 16 & 52.8 & 1.27 & 0.46 & \\
\hline Weekday & 2,489 & 9,191 & 68.9 & 34 & 98.5 & 1.07 & 0.28 & \\
\hline Year & & & & & & & & 0.26 \\
\hline 2003 & 375 & 1,079 & 8.1 & 4 & 8.2 & 0.76 & 0.44 & \\
\hline 2004 & 315 & 998 & 7.5 & 3 & 5.0 & 0.50 & 0.31 & \\
\hline 2005 & 345 & 1,226 & 9.2 & 7 & 14.0 & 1.14 & 0.46 & \\
\hline 2006 & 377 & $\mathrm{I}, 340$ & 10.0 & 4 & 8.7 & 0.65 & 0.34 & \\
\hline 2007 & 369 & 1,290 & 9.7 & 4 & 12.6 & 0.97 & 0.63 & \\
\hline 2008 & 378 & $\mathrm{I}, 432$ & 10.7 & 3 & 6.2 & 0.43 & 0.25 & \\
\hline 2009 & 383 & $\mathrm{I}, 483$ & II.I & 5 & 20.7 & $\mathrm{I} .40$ & 0.74 & \\
\hline 2010 & 437 & 1,618 & 12.1 & 6 & 11.8 & 0.73 & 0.32 & \\
\hline 2011 & 370 & 1,670 & 12.5 & 7 & 38.1 & 2.28 & 1.00 & \\
\hline 2012 & 300 & $1,20 \mid$ & 9.0 & 7 & 26.0 & 2.17 & 1.51 & \\
\hline Region & & & & & & & & 0.87 \\
\hline Northeast & 858 & 2,632 & 19.7 & 14 & 37.1 & $\mathrm{I} .4 \mathrm{I}$ & 0.51 & \\
\hline Midwest & 933 & 3,454 & 25.9 & 13 & 38.6 & 1.12 & 0.38 & \\
\hline South & 1,325 & 5,219 & 39.1 & 18 & 48.0 & 0.92 & 0.39 & \\
\hline West & 533 & 2,033 & 15.2 & 5 & 27.5 & 1.35 & 0.78 & \\
\hline Reason for visit & & & & & & & & 0.08 \\
\hline Symptoms of teeth and gums & 260 & 782 & 5.9 & 4 & 3.7 & 0.47 & 0.24 & \\
\hline Toothache & 3,297 & 12,200 & 91.5 & 43 & 136 & 1.11 & 0.25 & \\
\hline Gum pain/beeding gums & 92 & 356 & 2.7 & 3 & 11.9 & 3.33 & 2.39 & \\
\hline
\end{tabular}

acteristics and the bivariate relationships. It shows that $50 / 3,649$ visits in the sample, representing a weighted total of over 151,000 visits nationwide, were transported to the ED for NTP via ambulance. In the bivariate analysis, age and payment type were significantly associated with ED visits for tooth pain by an ambulance. There were no significant differences in ambulance use by sex, race/ethnicity, day of the week, year, geographic region or specific reason for ED visit.

Table 2 shows results from the multivariable logistic regression analyses. Compared to 25-44 year olds, 45-64 year olds had almost four times higher odds of an ED visit for NTP by ambulance. Public insurance was associated with marginally significantly higher odds of being trans- 
Table 2 Multivariable logistic regression: factors associated with the use of ambulance for nontraumatic tooth pain

\begin{tabular}{|c|c|c|c|c|c|}
\hline Predictor (reference) & Level & Odds ratio & 95\% Lower $\mathrm{Cl}$ & 95\% Upper Cl & $P$-value \\
\hline \multirow[t]{4}{*}{ Payment type (reference: private insurance) } & Unknown & 2.85 & 0.61 & 13.38 & 0.19 \\
\hline & Public insurance & 4.05 & 1.00 & 16.50 & 0.05 \\
\hline & Other & 3.49 & 0.48 & 25.46 & 0.22 \\
\hline & Uninsured & 1.37 & 0.32 & 5.89 & 0.67 \\
\hline \multirow[t]{4}{*}{ Age group (reference: $25-44$ years) } & $<15$ years & 1.78 & 0.41 & 7.80 & 0.44 \\
\hline & $15-24$ years & 1.76 & 0.74 & 4.18 & 0.20 \\
\hline & $45-64$ years & 3.53 & 1.22 & 10.24 & 0.02 \\
\hline & $\geq 65$ years & 1.80 & 0.32 & 10.05 & 0.51 \\
\hline Sex (reference: female) & Male & 1.28 & 0.58 & 2.83 & 0.54 \\
\hline \multirow[t]{2}{*}{ Race/ethnicity (reference: non-Hispanic White) } & Non-Hispanic Black & 1.09 & 0.41 & 2.86 & 0.87 \\
\hline & Hispanic & 2.11 & 0.78 & 5.74 & 0.14 \\
\hline Day of week (reference: weekday) & Weekend & 1.24 & 0.52 & 2.97 & 0.62 \\
\hline Year & -- & 1.16 & 0.99 & 1.36 & 0.07 \\
\hline \multirow[t]{3}{*}{ Region (reference: midwest) } & Northeast & 1.21 & 0.47 & 3.10 & 0.69 \\
\hline & South & 0.84 & 0.30 & 2.38 & 0.75 \\
\hline & West & 1.10 & 0.29 & 4.13 & 0.88 \\
\hline \multirow[t]{2}{*}{ Reason for visit (reference: toothache) } & Symptoms of teeth and gums & 0.40 & 0.13 & 1.23 & 0.11 \\
\hline & Gum pain/bleeding gums & 2.70 & 0.63 & 11.66 & 0.18 \\
\hline
\end{tabular}

Notes: Bold values are statistically significant, $p=0.05$.

ported to the ED by ambulance for tooth pain $(P=0.05)$. The year of data collection was not associated with ambulance use, despite an overall increase in the trend of ambulance use for ED visits for tooth pain over time. No other factors were significantly associated with ambulance use, including those reporting visits due to symptoms with teeth and gums $(P=0.11)$.

\section{Discussion}

In this study, we found that just over $1 \%$ of patients were transported by ambulance among those who had ED visits for NTP. This proportion might look small, but on a national scale, it does represent tens of thousands of seemingly wasteful and unnecessary ambulance calls. Such ambulance calls are not only costly in terms of direct expenditure, but also could potentially compromise ambulance availability for more urgent or life-threatening conditions. From a broader perspective, any visit to an ED for nontraumatic dental problems represents inefficiency in the system and lack of access to not only emergency dental services but also to routine dental services as well. Most treatments for dental problems in the ED are palliative and provide no treatment for the underlying disease or condition. In addition, with delayed definitive care, additional trips to the ED are usually made in the interim, leading to increase in dental care expenditure.

In this study, those on public insurance and those belonging to 45-64 years age group were more likely to visit the ED for nontraumatic dental pain by ambulance. This finding is in sharp contrast to previous results showing adults aged 19-42 years as being more likely to use and be frequent users of the ED for nontraumatic dental conditions. ${ }^{1,8}$ In addition, Okoro et al reported that adults aged 45-64 years had higher prevalence of insurance coverage compared to those aged 18-24 and 25-44 years. ${ }^{9}$ Therefore, the use of ambulance by these age groups could be related to their knowledge that having private insurance may potentially pay for transportation by ambulance for nontraumatic dental conditions to the ED as a covered service. However, our study data cannot verify this assumption and were not part of the research question; neither were we able to verify their dental care access. Notwithstanding, some of the reasons for the lack of access to dental care include inadequate number of dentists participating in publicly funded programs ${ }^{10}$ and lack of dental benefits for adults in many states, ${ }^{11}$ but ambulance services - no matter what the reason is - are routinely covered by public and private insurance programs. In addition, the 45-64 years age group may have more complex dental needs and are more likely to have comorbid conditions (eg, obesity), which may make it more difficult to access the ED by private vehicle or public transportation, making ambulance conveyance seem more necessary. On a general note, our finding of increased medically unnecessary transportation among publicly insured populations is consistent with previous study findings. ${ }^{12}$ One study documented higher odds of utilization of ambulance for transport among 45-64 year olds for other non-emergency conditions. ${ }^{13}$ 
To the best of our knowledge, this study is the first to examine the use of ambulances for conveying patients to the ED for nontraumatic dental pain. The study is based on nationally representative data with validated sampling weights. Therefore, the extrapolation of a relatively small number of cases of ED visits for NTP via ambulance may over- or underestimate the true occurrence. Some of the other possible shortcomings of our study include our use of self-reported data for the reason for ED visits. It is possible that a small proportion of subjects were conveyed by special public transportation systems or by vehicles not in use for emergency purposes (eg, police vehicles on routine patrol), but were miscoded as having arrived by ambulance in the data collection form. In addition, some miscoding may have occurred where traumatic injury to the mouth or face that truly required emergency care may have been coded as a more nontraumatic dental pain or tooth/gum problems. Furthermore, our study did not include information from experts and experienced paramedics who are in a position to tell whether these calls are appropriate or not. ${ }^{5}$

Nonetheless, our findings suggest that people in the USA are indeed transported to the ED for NTP via ambulance, and while this is not a common occurrence, it does occur with some frequency. The use of ambulances for this purpose has implications for overall health care costs and may negatively impact access to ED care for life-threatening conditions. Potential solutions could include engaging programs that utilize telehealth and social services within emergency medical services systems. These programs may be beneficial in helping those with NTP navigate away from EDs and facilitate provision of definitive dental care to these patients. ${ }^{14}$

\section{Acknowledgment}

All authors declare that the data analyzed are publicly available. This project was supported by the National Institute of Health grant \#1R03DE024494-01.

\section{Disclosure}

The authors report no conflicts of interest in this work.

\section{References}

1. Okunseri C, Okunseri E, Thorpe JM, Xiang Q, Szabo A. Patient characteristics and trends in nontraumatic dental condition visits to emergency departments in the United States. Clin Cosmet Investig Dent. 2012;4:1-7.

2. Allareddy V, Rampa S, Lee MK, Allareddy V, Nalliah RP. Hospital-based emergency department visits involving dental conditions: profile and predictors of poor outcomes and resource utilization. JAm Dent Assoc. 2014;145(4):331-337.

3. Bailey M. Ambulance Trip can leave you with surprising and very expensive bills. November 20, 2017. The Washington Post; 2017. Available from: https://www.washingtonpost.com/national/health-science/ ambulance-trips-can-leave-you-with-surprising-and-very-expensivebills/2017/11/17/6be9280e-c313-11e7-84bc-5e285c7f4512_story. html?utm_term=.0de331bd0140. Accessed March 13, 2018.

4. Richards JR, Ferrall SJ. Inappropriate use of emergency medical services transport: comparison of provider and patient perspectives. Acad Emerg Med. 1999;6(1):14-20.

5. Dejean D, Giacomini M, Welsford M, Schwartz L, Decicca P. Inappropriate Ambulance Use: A Qualitative Study of Paramedics' Views. Healthcare Policy / Politiques de Santé. 2016;11(3):67-79.

6. Meisel ZF, Pines JM, Polsky D, Metlay JP, Neuman MD, Branas CC. Variations in ambulance use in the United States: the role of health insurance. Acad Emerg Med. 2011;18(10):1036-1044.

7. Mazer-Amirshahi M, Sun C, Mullins P, Perrone J, Nelson L, Pines JM. Trends in Emergency Department Resource Utilization for PoisoningRelated Visits, 2003-2011. J Med Toxicol. 2016;12(3):248-254.

8. Okunseri C, Pajewski NM, Jackson S, Szabo A. Wisconsin Medicaid enrollees' recurrent use of emergency departments and physicians' offices for treatment of nontraumatic dental conditions. J Am Dent Assoc. 2011;142(5):540-550.

9. Okoro CA, Zhao G, Fox JB, Eke PI, Greenlund KJ, Town M. Surveillance for Health Care Access and Health Services Use, Adults Aged 18-64 Years - Behavioral Risk Factor Surveillance System, United States, 201466 (No. MMWR Surveill Summ SS. 2017;7:1-42.

10. General Accounting Office. Oral health: Dental disease is a chronic problem among low-income populations-United States. General Accounting Office. Report to congressional requester. HEHS-00-72; 2000. Available from: http://www.gao.gov/products/GAO/HEHS-00-72. Accessed April 26, 2000.

11. U.S. Department of Health and Human Services. Oral Health in America: A Report of the Surgeon General. Rockville, MD: Department of Health and Human Services, National Institute of Dental and Craniofacial Research, National Institutes of Health; 2000.

12. Solberg RG, Edwards BL, Chidester JP, Perina DG, Brady WJ, Williams MD. The prehospital and hospital costs of emergency care for frequent ED patients. Am J Emerg Med. 2016;34(3):459-463.

13. Ting JY, Chang AM. Path analysis modeling indicates free transport increases ambulance use for minor indications. Prehosp Emerg Care. 2006;10(4):476-481.

14. Langabeer JR, Gonzalez M, Alqusairi D, et al. Telehealth-Enabled Emergency Medical Services Program Reduces Ambulance Transport to Urban Emergency Departments. West J Emerg Med. 2016;17(6):713-720.
Clinical, Cosmetic and Investigational Dentistry

Publish your work in this journal

Clinical, Cosmetic and Investigational Dentistry is an international, peer-reviewed, open access, online journal focusing on the latest clinical and experimental research in dentistry with specific emphasis on cosmetic interventions. Innovative developments in dental materials, techniques and devices that improve outcomes and patient satisfac-

\section{Dovepress}

tion and preference will be highlighted. The manuscript management system is completely online and includes a very quick and fair peerreview system, which is all easy to use. Visit http://www.dovepress. com/testimonials.php to read real quotes from published authors. 